\title{
THE INFLUENCE OF DIATOMITE ROCK ON HUMUS SUBSTANCES OF SOD-PODSOLIC SOIL IN CONDITIONS OF AGRO ECOSYSTEMS AND PHYSICAL-CHEMICAL MECHANISM OF THEIR INTERACTION
}

(C) 2020

Kozlov Andrey Vladimirovich, candidate of biological sciences, associate professor of Ecological Education and Rational Environmental Management Department Minin Nizhny Novgorod State Pedagogical University (Nizhny Novgorod, Russian Federation)

Kulikova Alevtina Khristoforovna, doctor of agricultural sciences, professor, head of Soil Science, Agrochemistry and Agroecology Department Ulyanovsk State Agrarian University named after P.A. Stolypin (Ulyanovsk, Russian Federation)

Rumyantsev Ruslan Ivanovich, master student

of Biology, Chemistry and Biological and Chemical Education Department Minin Nizhny Novgorod State Pedagogical University (Nizhny Novgorod, Russian Federation)

Abstract. The paper provides an assessment of physical and chemical changes of humus substances in the sludgecolloidal fraction, isolated from the sod-podsolic sandy loamy soil, during its interaction with the diatomite rock of the Inzen deposit in conditions of agro ecosystem of the Nizhny Novgorod Region. The experience was a 3-year (2015-2017) microfield experiment, laid down on one of the fields of «Elitkhoz». The diatomite was added to soil once during the summer season of 2014 in doses of 3, 6 and $12 \mathrm{t} / \mathrm{ha}$, on which winter wheat, barley and peas were subsequently grown (varieties are zoned in the Volga-Viatskiy Region). Each year, upon completion of crop cultivation, a silo-colloidal fraction was isolated from selected soil samples by the Kachinsky gravimetric method and analyzed on an IR-Fourier-spectrometer, determining absorption spectra in frequency range of $4000-400 \mathrm{~cm}^{-1}$. In soil samples the content of specific organic substance (humus) was also determined by the Thurin method with spectrophotometric termination. The studies revealed that interaction of diatomite with the organic soil matrix resulted in organosilanes $\mathrm{R}_{n} \mathrm{SiH}_{4-\mathrm{n}}\left(930 \mathrm{~cm}^{-1}\right)$, organosilanes oxygen-free $\mathrm{Si}_{-} \mathrm{CH}_{3}\left(1253 \mathrm{~cm}^{-1}\right)$ and oxygen-containing compounds $\mathrm{Si}-\mathrm{O}-\mathrm{CH}_{3}$ $\left(1110 \mathrm{~cm}^{-1}\right)$, as well as siloxane bonds of Si-O-Si $\left(570 \mathrm{~cm}^{-1}\right)$. The obtained facts directly indicate formation of siliconcontaining organo-mineral complexes in sludge-colloidal fraction and participation of silicon in their formation. It is evident that an active diatomite represented by various silicon acids $\left(\mathrm{H}_{\mathrm{n}} \mathrm{SiO}_{\mathrm{m}}\right)$ was involved in formation of these bonds. The use of diatomite has helped to maintain content of humus substances in soil at the control level, which can also confirm effects of interaction of silicon substances with organic part and, as a result, prevent its degradation. Based on the obtained results and analysis of scientific literature, a mechanism is proposed for possible physical-chemical interaction of active silicon substances with an organic component of the sludge-colloidal fraction of the sod-podsolic soil, which consists in polymerization of silicon on organo-mineral complexes (bonds - $\mathrm{Si}-\mathrm{O}-\mathrm{Si}$-), as well as in interaction of the hydrolyzed part of humus substances with silicon with subsequent formation of organosilanes, which are subsequently connected with an organic Si-O- $\mathrm{CH}_{3}$ matrix. Due to the fact that organic matter of soils is involved in the formation of ecological stability of soil cover the established effects make it possible to speak about the increase of agro ecological stability of humus substances in sod-podsolic soil due to the use of diatomite rocks.

Keywords: soil cover; sod-podsolic sandy loam soil; biogeocenosis; fertility; diatomite rock of Inzen deposit; infrared spectroscopic analysis; soil organic matter; sludge-colloidal fraction of soil; siliceous reactionary and active centers; maintenance of humus; ecological stability of agro ecosystem of sod-podsolic soil; biogeocenotic and ecological functions; stability of land ecosystems.

\section{СРАВНИТЕЛЬНАЯ ОЦЕНКА СОСТОЯНИЯ ОКРУЖАЮЩЕЙ СРЕДЫ С ПОМОЩЬЮ РАСТЕНИЙ-БИОИНДИКАТОРОВ В УСЛОВИЯХ РАЗЛИЧНОГО АНТРОПОГЕННОГО ВОЗДЕЙСТВИЯ ГОРОДОВ САРАНСК И ИНСАР}

(C) 2020

Лабутина Марина Викторовна, кандидат биологических наук, доцент кафедры биологии, географии и методик обучения

Маскаева Татьяна Александровна, кандидат биологических наук, доцент кафедры биологии, географии и методик обучения

Чегодаева Нина Дмитриевна, кандидат сельскохозяйственных наук, доцент кафедры биологии, географии и методик обучения

Курынова Евгения Александровна, магистрант кафедры биологии, географии и методик обучения Мордовский государственный педагогический институт имени М.Е. Евсевьева (2. Саранск, Российская Федерация)

Аннотация. В статье приведены результаты изучения реакции березы бородавчатой как основной городской культуры, используемой в озеленении городов, на разный уровень антропогенного воздействия. Ежегодные исследования свидетельствуют о том, что в регионе нет устойчивой тенденции по снижению техно- 
генных выбросов. Озеленение крупных промышленных центров имеет важное средоохранное значение. По морфометрическим и некоторым репродуктивным параметрам у березы отмечается адаптивная реакция на условия окружающей среды. Проведенные исследования показали, что условия среды обитания непосредственно воздействуют на морфометрические и репродуктивные характеристики растений. В большей степени в условиях возрастания антропогенного воздействия проявляется реакция биоморфологических параметров березы бородавчатой. При использовании метода флуктуирующей асимметрии, его интегральные показатели проявили реакцию растений на возрастание техногенного воздействия в условиях города. Показательными в этом отношении являются всхожесть и энергия прорастания семян березы, собранные с разных исследуемых участков. Вариативный коэффициент по размерам плодов и проростков выявил, как правило, очень высокую изменчивость (20-40\%), что объясняет высокую пластичность растений к условиям обитания даже на ранних этапах их развития.

Ключевые слова: антропогенное загрязнение; окружающая среда; озеленение; экологический мониторинг; растения-биоиндикаторы; береза бородавчатая; флуктуирующая асимметрия; интегральный показатель; анатомо-морфологические адаптации; генеративные органы; всхожесть семян; энергия прорастания; ростовые показатели.

\section{Введение}

Озеленение крупных промышленных центров имеет важное средоохранное значение. Зеленые растения в городе выполняют не только декоративнопланировочную, но и санитарно-гигиеническую роль $[1$, с. 89]. Они снижают уровень шума и загрязнения пылью и газами, защищают от ветров и увлажняют сухой воздух. Выделяя биологически активные вещества - фитонциды - они убивают или сильно тормозят развитие болезнетворных микроорганизмов. Однако зеленые растения в городе постоянно испытывают на себе отрицательно действующее техногенное загрязнение [2, с. 1654].

Основными источниками загрязнений являются предприятия электроэнергетики, строительных материалов, светотехнической промышленности, а также растущее из года в год количество объектов автотранспорта. Промышленное и автотранспортное загрязнение городов способствует возникновению многочисленных хронических заболеваний [3].

В условиях Республики Мордовия 39\% населения проживает в условиях постоянного воздействия загрязняющих веществ [4, с. 15]. Ежегодные исследования свидетельствуют о том, что в регионе нет устойчивой тенденции по снижению выбросов, а в отдельные годы, наоборот, наблюдается увеличение количества выбросов от промышленных предприятий $[5$, c. 21]. Поэтому с каждым годом важнейшее значение приобретает проблема изучения жизнедеятельности древесных растений в городских условиях. Находясь под постоянным техногенным воздействием, зеленые растения вынуждены приспосабливаться к нему с помощью анатомо-морфологических и физиолого-биохимических адаптаций.

Одним из основных методов, применяемых для оценки состояния экосистем крупных городов, является мониторинг зеленых насаждений. Целью мониторинга является получение исходных данных для многофакторного корреляционного анализа состояния растений и совокупности воздействующих факторов; создание банка данных о состоянии зеленых насаждений в целом по городу с учетом многообразия растительности, факторов воздействия, многовариантности мер по сохранению и защите зеленых насаждений; разработка рекомендаций по подбору ассортимента древесных и кустарниковых пород в зависимости от условий среды и видов негативного воздействия [6, с. 32]. В рамках мониторинга может исследоваться биоразнообразие растений, опреде- ляться возрастной состав, репродуктивные возможности [7, с. 141], цитогенетические исследования [8].

Этому направлению изучения окружающей среды много внимания уделяется на кафедре биологии, географии и методик обучения Мордовского государственного педагогического института имени М.Е. Евсевьева (МГПИ). Преподаватели для проведения мониторинговых работ часто привлекают школьников города, а результаты такой деятельности находят свое отражение в школьных научно-исследовательских работах, с которыми учащиеся выступают на различных экологических конференциях и конкурсах [9, с. 107].

Часто состояние растений оценивается по доле усыхающих и сухостойных деревьев как хорошее, удовлетворительное или неудовлетворительное. Кроме этого, производится подробная морфометрическая характеристика, учитываются физические повреждения. Из вышеперечисленного наиболее важными с точки зрения характеристики состояния растений являются показатели степени усыхания деревьев. Следует отметить, что использование этих показателей возможно, когда влияние неблагоприятных факторов уже привело к достаточно серьезным нарушениям состояния деревьев и нарушения эти имеют зачастую необратимый характер [10, с. 53].

В то же время существует острая необходимость в дополнительных показателях для более тонкого контроля состояния растений - системы раннего реагирования для обнаружения начальных стадий ухудшения ситуации, когда при принятии соответствующих мер еще можно поправить дело. В этом случае лучше учитывать показатели состояния организмов разных видов.

В качестве объектов для тонкой оценки состояния зеленых насаждений предлагаются разные виды древесных растений: березу повислую (Betula pendula Roth), липу мелколистную (Tilia cordata Mill.), тополь черный (Populis nigra L.), каштан конский (Aesculus hippocostanum L.) и др.

На территории г. Саранска в зеленых насаждениях наиболее распространена береза бородавчатая (повислая). Betula pendula Roth - одна из наиболее выносливых местных пород и имеет широкую экологическую амплитуду. Растет на сухих и влажных песчаных, суглинистых, черноземных и щебнистых почвах. В естественных условиях растет быстро, хорошо возобновляется порослью и самосевом [11, с. 83].

Наиболее распространенным из биоиндикационных методов является метод флуктуирующей асимметрии организмов $[12$, с. $26 ; 13$, с. 160]. Под флук- 
Лабутина М.В., Маскаева Т.А., Чегодаева Н.Д., Курынова Е.А.

туирующей асимметрией понимают незначительные и случайные отклонения от строгой билатеральной симметрии живых объектов или их частей. Флуктуирующая асимметрия позволяет оценить нестабильность развития организма, ее уровень будет минимальным лишь при оптимальных условиях среды и возрастает при любых стрессовых воздействиях $[14$, c. $16 ; 6$, c. 24$]$.

\section{Место и методы исследования}

Исследования проводились осенью 2016-2017 гг. в двух городах Республики Мордовия: г. Саранск столица республики - крупный культурный и промышленный центр; г. Инсар - районный центр Инсарского района Республики Мордовия. Березовые листья были собраны произвольно с растущих деревьев приблизительно одного возраста в следующих точках г. Саранска: 1-й - в березовых посадках зеленой зоны МГПИ в юго-западной части города; 2-й около завода АО «Биохимик», в промышленном центре города. В г. Инсар участки располагались: 3-й - в смешанном лесу в 3-х км от г. Инсар; 4-й - около АО «Неон», занимающейся производством электротехнических машин, оборудования и аппаратуры.

При сборе материала для определения флуктуирующей асимметрии строго придерживались методических требований В.М. Захарова и др. [15].

В качестве критериев оценки антропогенного воздействия рассматривались энергия прорастания, всхожесть семян, раннее развитие корешков и проростков. Энергия прорастания и всхожесть семян определены в соответствии с ГОСТ 13056.6-98 [16]. Для определения всхожести семян и энергии прорастания с каждого участка отбирались по 100 семян в 3-х повторностях.

Для проведения биометрических исследований раннего развития предварительно проращивали проростки до 4-х дневного возраста. У образцов измеряли длину корешков и побега, а также определяли коэффициент изменчивости данных параметров.

\section{Результаты исследования и их обсуждение}

В ходе проведенного исследования 2016-2017 гг. мы определили уровень флуктуирующей асимметрии у листовых пластинок березы бородавчатой в разных условиях антропогенного воздействия, что позволило определить состояние здоровья среды, в которой растут деревья (таблица 1$)$.

Анализируя данные таблицы 1 , можно сделать вывод о том, что на всех выбранных участках интегральный показатель флуктуирующей асимметрии различен, что свидетельствует о разной степени ан- тропогенной нагрузки на тот или иной исследуемый участок. Минимальным коэффициентом характеризуется выборка листьев березы в смешанном лесу у г. Инсара $(0,030-0,039)$, здесь качество среды согласно классификации можно оценить как «условно нормальное». В зеленой зоне МГПИ интегральный показатель $(0,043-0,046)$ характеризует местность как «средний уровень отклонения от нормы», это говорит о том, что растения в этом районе испытывают среднее влияние неблагоприятных факторов. Очевидно, что показатели стабильности развития у выборок, взятых около заводов $(0,056-0,070-$ «Неон», 0,077-0,093 - «Биохимик»), указывают на высокий уровень антропогенного воздействия. Это доказывает, что неблагоприятное состояние окружающей среды районов заводов «Биохимик» и «Неон» находит отражение в показателях асимметрии листьев березы бородавчатой - он становится выше.

Замечено, что не только вегетативные, но и генеративные органы древесных растений реагируют на антропогенные воздействия. От негативного техногенного воздействия страдают цветки, семена и плоды [17, с. 69], снижается качество пыльцы [18, с. 179; 19, c. 605].

Плоды березы продолговато-эллиптические, с крылышками, в 2-3 раза превышающими по ширине орешек. Семена жёлтые, 1,5-2 мм длиной и 1 мм шириной. Вес 1 тыс. семян 0,17-0,2 г. Цветет береза в мае, до распускания листьев [11, с. 84]. Плоды созревают в августе-сентябре и начинают рассеиваться с конца лета до середины зимы. Плодоношение ежегодное, начинается с 20-25 лет.

Проращивание семян березы, собранных на исследуемых участках с разным уровнем антропогенного воздействия показала неодинаковый уровень всхожести и энергии прорастания (рис. 1).

Максимальная всхожесть семян (52\%) и энергия прорастания (34\%) отмечалась у семян березы в смешанном лесу у г. Инсар. Несколько ниже эти показатели отмечены в зеленой зоне МГПИ (45\% и $21 \%$ соответственно). В условиях интенсивного антропогенного воздействия (заводы «Биохимик» в Саранске и «Неон» в Инсаре) всхожесть семян снизилась почти в 2 раза, энергия прорастания - в 3 и более раз.

Размеры плодов березы в выборках по участкам были в среднем относительно постоянными (5,25,8 мм), однако коэффициент изменчивости по высоте и ширине - значителен (таблица 2). По исследуемым признакам получены достоверные результаты.

Таблица 1 - Величина асимметрии листовой пластинки Betula pendula

\begin{tabular}{|c|c|c|c|}
\hline $\begin{array}{c}\text { Место } \\
\text { исследования }\end{array}$ & $\begin{array}{c}\text { Величина } \\
\text { асимметрии листа }\end{array}$ & $\begin{array}{c}\text { Оценка состояния, } \\
\text { балл }\end{array}$ & Качество среды \\
\hline \multicolumn{5}{|c|}{2016 г. } \\
\hline участок 1 & 0,043 & 2 & начальные (незначительные) отклонения от нормы \\
\hline участок 2 & 0,093 & 5 & критическое состояние \\
\hline участок 3 & 0,039 & 1 & условно нормальное \\
\hline участок 4 & 0,056 & 5 & критическое состояние \\
\hline \multicolumn{5}{|c|}{2017 г. } \\
\hline участок 1 & 0,046 & 3 & средний уровень отклонений от нормы \\
\hline участок 2 & 0,077 & 5 & критическое состояние \\
\hline участок 3 & 0,030 & 1 & условно нормальное \\
\hline участок 4 & 0,070 & 4 & существенные (значительные) отклонения от нормы \\
\hline \hline
\end{tabular}


Как видно из таблицы 2, максимальная длина и ширина плодов наблюдается в местах с интенсивной антропогенной нагрузкой: г. Саранск - завод «Биохимик», г. Инсар - завод «Неон», отличия семян по ширине менее значительны, чем по длине.

Одним из показателей морфологической изменчивости является коэффициент изменчивости $\left(\mathrm{C}_{\mathrm{V}}\right)$. Он не зависит от единиц измерения, поэтому удобен для сравнительной оценки различных выборочных совокупностей - он позволяет получить информацию об особенностях норм реакций разных видов растений и их признаков [20, с. 228].

Наглядно коэффициенты изменчивости исследуемых признаков плодов березы представлены в таблице 2 и на рисунке 2. Результаты показывают, что коэффициент изменчивости может существенно колебаться.

При сравнении значений $\mathrm{C}_{\mathrm{V}}$ по всем участкам наибольшее значение коэффициента вариации (47\%) по длине плода наблюдается в районе завода «Неон», в то же время коэффициент вариации по ширине плода на этом участке минимальный. Наибольшее значение $\mathrm{C}_{\mathrm{V}}$ по ширине плода (38\%) мы видим на участке смешанного леса в Инсарском районе.

Известно, что если коэффициент вариации меньше $10 \%$ - изменчивость незначительная, больше $10 \%$, но меньше $20 \%$ - изменчивость средняя; если больше $20 \%$ - изменчивость значительная [20]. На

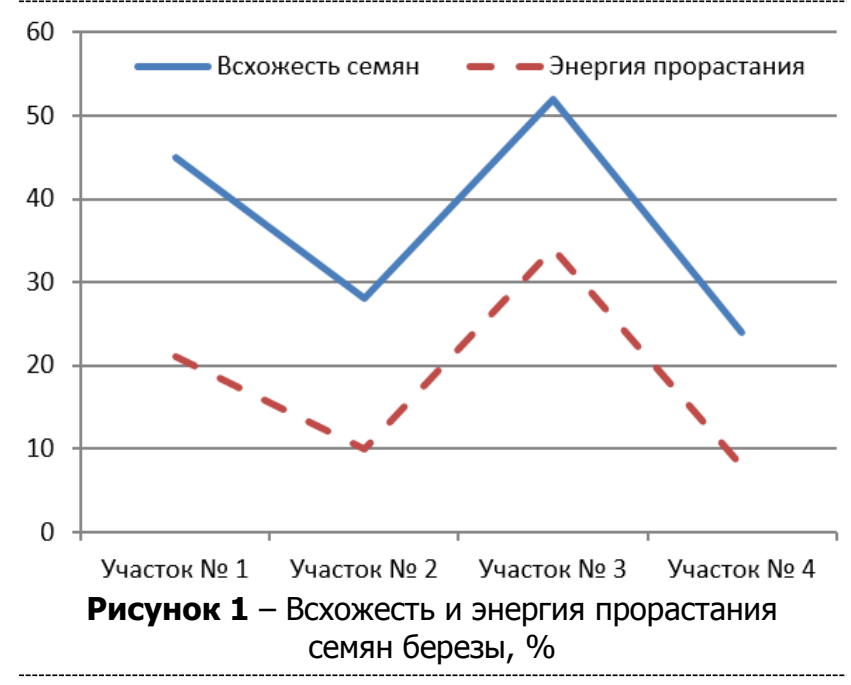

основании полученных результатов мы можем сделать вывод о том, что коэффициент вариации на всех участках больше $20 \%$ - это свидетельствует о значительной изменчивости признака на всех участках.

Прорастание семян является одним из самых сложных и важных этапов в онтогенезе растений. На ранние ростовые показатели влияют как внутренние, так и внешние факторы, в том числе и вещества, которые накапливаются в процессе жизнедеятельности в растениях.

Проращивание семян березы с разных участков и получение из них проростков, выявило неодинаковый темп их прорастания (таблица 3 ). Максимальной (25-26 мм) длина проростков наблюдалась на участках в смешанном лесу (Инсарский район) и зеленой зоне МГПИ (г. Саранск), размеры проростков на этих участках достоверно различимы. Однако длина корней на этих участках была меньше по сравнению с участками с техногенным воздействием (таблица 3 , рисунок 3 ).

Коэффициент вариации по длине стебля проростков березы исследуемых участков колебался от среднего $(15 \%)$ до значительного (20-22\%). Изменчивость длины корней проростков была очень значительной $30-53 \%$, особенно она была высока у прорастающих семян, собранных с территории АО «Неон».

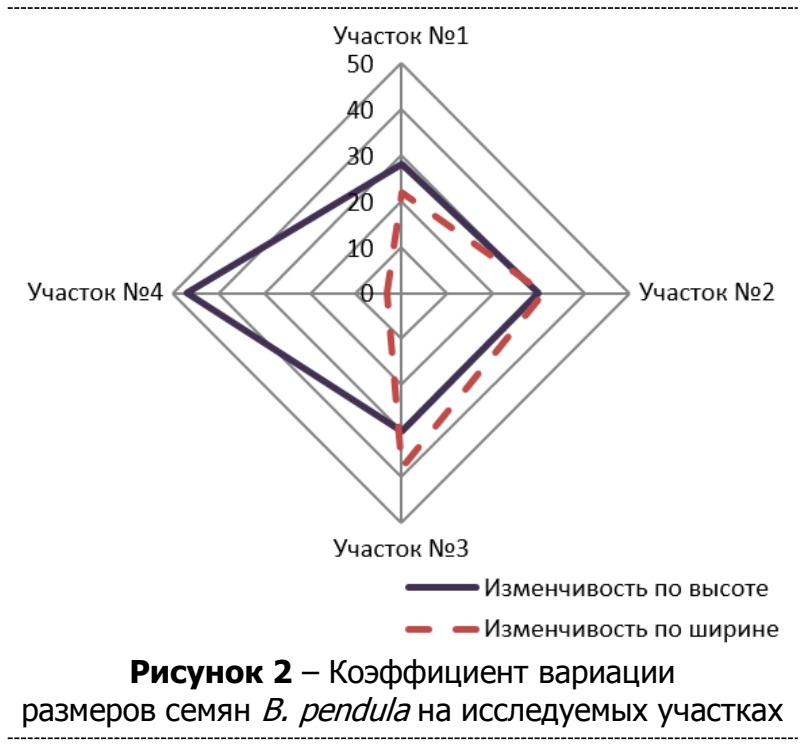

Таблица 2 - Размеры плодов и коэффициент вариации березы бородавчатой

\begin{tabular}{|c|c|c|c|c|}
\hline $\begin{array}{c}\text { Место } \\
\text { исследования }\end{array}$ & $\begin{array}{c}\text { Длина плода, } \\
\text { мм }(\mathrm{M} \pm \mathrm{m})\end{array}$ & $\begin{array}{c}\mathrm{C}_{\mathrm{V}} \text { по длине плода, } \\
\%\end{array}$ & $\begin{array}{c}\text { Ширина плода, } \\
\text { мм }(\mathrm{M} \pm \mathrm{m})\end{array}$ & $\begin{array}{c}\mathrm{C}_{\mathrm{V}} \\
\text { по ширине плода, \% }\end{array}$ \\
\hline Участок № 1 & $5,1 \pm 0,76$ & 28 & $3,1 \pm 0,13$ & 22 \\
\hline Участок № 2 & $6,0 \pm 0,36^{*}$ & 30 & $3,2 \pm 0,21$ & 31 \\
\hline Участок № 3 & $5,2 \pm 0,31^{*}$ & 30 & $3,1 \pm 0,42$ & 38 \\
\hline Участок № 4 & $5,4 \pm 0,51$ & 47 & $3,2 \pm 0,25$ & 3,1 \\
\hline
\end{tabular}

Примечание. Отличие достоверно при * $\mathrm{p}<0,05$.

Таблица 3 - Ранние ростовые показатели и их изменчивость у Betula pendula

\begin{tabular}{|c|c|c|c|c|}
\hline Место исследования & Длина стебля, мм & $\mathrm{C}_{\mathrm{V}}$ & Длина корня, мм & $\mathrm{C}_{\mathrm{V}}$ \\
\hline Участок № 1 & $26,4 \pm 0,76^{*}$ & 20 & $5,8 \pm 0,29^{*}$ & 30 \\
\hline Участок № 2 & $18,4 \pm 0,71$ & 20 & $7,8 \pm 0,71$ & 49 \\
\hline Участок № 3 & $25,9 \pm 0,89^{*}$ & 22 & $6,9 \pm 0,51^{*}$ & 40 \\
\hline Участок № 4 & $17,3 \pm 0,56$ & 15 & $8,4 \pm 1,65$ & 53 \\
\hline
\end{tabular}

Примечание. Отличие достоверно при * $\mathrm{p}<0,05$. 
Лабутина М.В., Маскаева Т.А., Чегодаева Н.Д., Курынова Е.А.

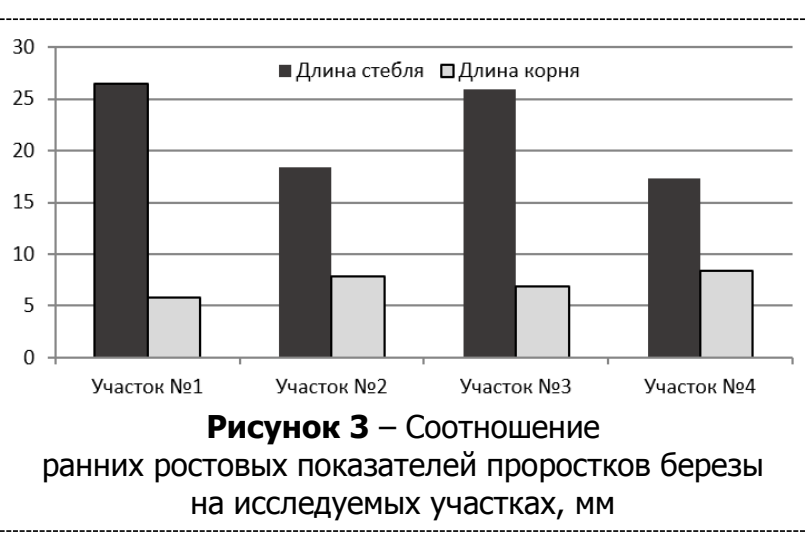

Bыводы

Таким образом, проведенные исследования показали, что условия среды обитания непосредственно воздействуют на морфометрические и репродуктивные характеристики растений. В большей степени в условиях возрастания антропогенного воздействия проявляется реакция биоморфологических параметров березы бородавчатой. При использовании метода флуктуирующей асимметрии его интегральные показатели показали реакцию растений на возрастание техногенного воздействия в условиях города. Показательными в этом отношении являются всхожесть и энергия прорастания семян березы, собранных с разных исследуемых участков. Вариативный коэффициент по размерам плодов и проростков выявил, как правило, очень высокую изменчивость (20-40\%), что объясняет высокую пластичность растений к условиям обитания даже на ранних этапах их развития.

\section{Список литературы:}

1. Хлебова Л.П., Ерещенко О.В. Качество пыльцы березы повислой (Betula pendula Roth) в условиях Барнаула // Известия Алтайского государственного университета. Биологические науки. 2012. № 3-1 (75). С. $89-92$.

2. Беляева Ю.В. Результаты исследования водоудерживающей способности листовых пластинок Betula pendula, произрастающей в условиях антропогенного воздействия // Известия Самарского научного центра РАН. 2014. Т. 16, № 5 (5). С. 1654-1659.

3. Ушаков И.С. Сравнительный временной анализ загрязнения атмосферного воздуха на территории республики Мордовия с 2000 по 2016 год [Электронный ресурс] // Современные проблемы территориального развития: электронный журнал. 2017. № 3. https://terjournal.ru/wpcontent/uploads/2017/10/ID21.pdf.

4. Каверин А.В., Щанкин А.А., Бызгаев В.А. Экологический риск заболеваний населения Республики Мордовия: монография. Саранск: Мордовский гос. пед. ин-т им. М.Е. Евсевьева, 2012. 115 с.

5. Государственный доклад о состоянии и об охране окружающей среды в Республике Мордовия в 2016 году / редкол.: В.Т. Шумкин, В.М. Максимкин, А.Н. Макейчев, И.А. Новиков [и др.]. Саранск, 2017. 235 с.

6. Состояние зеленых насаждений и городских лесов в Москве. Аналитический доклад по данным мониторинга 1999 г. / под ред. Х.Г. Якубова. М.: Прима-Пресс, 2000. 227 с.

7. Кокорина Н.В., Татаринцев П.Б. Методические вопросы выбора тест-объектов биоиндикации с использованием алгоритма сравнения коэффициентов вариации // Вестник Томского государственного унта. Биология. 2010. № 3 (11). С. 141-150.

8. Маскаева Т.А., Лабутина М.В., Чегодаева Н.Д. Исследование оценки степени генотоксичности почвы у предприятия ООО «Саранский завод керамических изделий» // Современные проблемы науки и образования. 2017. № 5. - https://science-education.ru/ru/ article/view?id=26874.

9. Лапшина М.В., Маскаева Т.А., Лабутина М.В. Роль экспериментальной исследовательской деятельности в дополнительном биологическом образовании детей // Гуманитарные науки и образование. 2019. T. 10, № 1. С. 107-111.

10. Экология большого города: альманах / под ред. Е.И. Пупырева. М.: Прима-Пресс, 1996. 180 с.

11. Валягина-Малютина Е.Т. Деревья и кустарники Средней полосы Европейской части России. Иллюстрированный определитель. СПб.: Специальная литература, 1998. 369 с.

12. Ерещенко О.В., Хлебова Л.П. Изменение морфометрических параметров листовой пластинки березы повислой Betula pendula Roth в условиях Барнаула // Известия Алтайского государственного университета. 2013. № 3-2 (79). С. 26-30.

13. Трубина Л.К., Храмова Е.П., Луговская А.Ю. Оценка качества окружающей среды урбанизированных территорий по величине флуктуирующей асимметрии листа // Интерэкспо Гео-Сибирь. 2013. T. 4, № 2. С. 160-163.

14. Лабутина М.В., Аникина Е.А. Оценка состояния города по асимметрии листьев // Евсевьевские чтения. Серия: Актуальные проблемы биологии, химии и методик обучения: сб. науч. тр. по мат-лам междунар. науч.-практ. конф. с элементами науч. школы для молодых ученых «51-е Евсевьевские чтения», 15-16 мая 2015 г. Саранск: Мордовский государственный педагогический институт имени М.Е. Евсевьева, 2016. С. 16-20.

15. Захаров В.М., Баранов А.С., Борисов В.И. и др. Здоровье среды: методика оценки, оценка состояния природных популяций по стабильности развития: методическое руководство для заповедников. М.: Центр экологической политики России, 2000. 68 с.

16. ГОСТ 13056.6-98 Межгосударственный стандарт «Семена деревьев и кустарников. Метод определения всхожести. Межгосударственный совет по стандартизации, метрологии и сертификации». Мн., 1997.

17. Лабутина М.В., Маскаева Т.А., Чегодаева Н.Д. Некоторые репродуктивные параметры Tilia cordata Mill. в условиях города Саранска // Самарский научный вестник. 2018. Т. 7, № 4 (25). С. 69-74. DOI: 10.24411/2309-4370-2018-14112.

18. Лабутина М.В. Мониторинг загрязнения окружающей среды по жизнеспособности пыльцы высших растений // Окружающая среда: экологические и медицинские проблемы: материалы науч.-практ. конф. / под ред. О.С. Шубиной, Н.А. Мельниковой. Саранск: Мордов. пед. ин-т, 2012. С. 179-182.

19. Тужилова Л.И. Палинологические методы биоиндикации: определение абортивных пыльцевых зерен и жизнеспособности пыльцы (по Шардакову) // Известия ПГПУ им. В.Г. Белинского, 2011. № 25. С. 605-609.

20. Доспехов Б.А. Методика полевого опыта. М.: Агропромиздат, $1985.351 \mathrm{c.}$ 
Исследование выполнено в рамках гранта на проведение научно-исследовательских работ по приоритетным направлениям научной деятельности вузов-партнеров по сетевому взаимодействию (Пермский государственный гуманитарно-педаго- гический университет и Мордовский государственный педагогический институт им. М.Е. Евсевьева) по теме: "Мониторинг качества окружающей среды с помощью растений-биоиндикаторов».

\title{
A COMPARATIVE ENVIRONMENTAL ASSESSMENT USING BIOINDICATOR PLANTS IN CONDITIONS OF ANTHROPOGENIC IMPACT OF SARANSK AND INSAR
}

(C) 2020

Labutina Marina Viktorovna, candidate of biological sciences, associate professor of Biology, Geography and Methods of Teaching Department

Maskaeva Tatiana Aleksandrovna, candidate of biological sciences, associate professor of Biology, Geography and Methods of Teaching Department

Chegodaeva Nina Dmitrievna, candidate of agricultural sciences, associate professor of Biology, Geography and Methods of Teaching Department

Kurynova Evgeniya Aleksandrovna, master student of Biology, Geography and Methods of Teaching Department Mordovian State Pedagogical Institute named after M.E. Evseviev (Saransk, Russian Federation)

Abstract. The paper studies the reaction of pendent white birch (Betula verrucosa) as the main urban culture used in urban greening at different levels of anthropogenic impact. Annual studies indicate that there is no sustainable trend to reduce man-made emissions in the region. Greening of large industrial centers is of great environmental importance. According to morphometric and some reproductive parameters, the birch has an adaptive response to environmental conditions. The studies have shown that habitat conditions directly affect the morphometric and reproductive characteristics of plants. To a greater extent, in conditions of anthropogenic impact increase, the reaction of biomorphological parameters of the pendent white birch is manifested. When using the method of fluctuating asymmetry, its integral indicators showed the reaction of plants to the increase in anthropogenic impact in the city. The germination and germination energy of birch seeds collected from different study sites are indicative in this respect. The variable coefficient on the size of fruits and seedlings revealed, as a rule, a very high variability (20-40\%), which explains the high plasticity of plants to living conditions even at the early stages of their development.

Keywords: anthropogenic pollution; environment; gardening; ecological monitoring; plants-bioindicators; pendent white birch (Betula verrucosa); fluctuating asymmetry; integral index; anatomical and morphological adaptations; generative organs; seed germination; germination energy; growth indicators.

$* * *$ КАК ИНДИКАТОРА ЭКОЛОГИЧЕСКОГО СОСТОЯНИЯ ВОДНОЙ СРЕДЫ НИЗОВИЙ Р. КАМЫ (C) 2020

\author{
Любин Павел Анатольевич, кандидат биологических наук, \\ старший научный сотрудник лаборатории гидробиологии \\ Зиганшин Ирек Ильгизарович, кандидат географических наук, доцент, \\ старший научный сотрудник лаборатории биогеохимии \\ Институт проблем экологии и недропользования Академии наук Республики Татарстан \\ (г. Казань, Российская Федерация)
}

\footnotetext{
Аннотаџия. Проведено исследование зоопланктона в нижнем течении реки Камы, крупнейшего притока Волги, имеющего важное экономическое значение для европейской части России. Полученные результаты позволили установить летний состав фауны зоопланктона исследуемого водоема, определить количественные характеристики сообществ. Был выявлен 61 таксон, относящийся к 3 типам: Rotifera, Arthropoda (группы Cladocera, Copepoda) и Mollusca (Bivalvia). В среднем по району исследования видовая плотность составляет

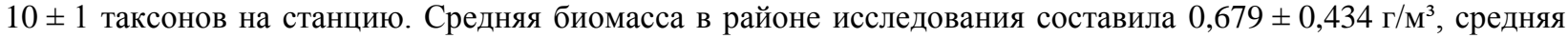

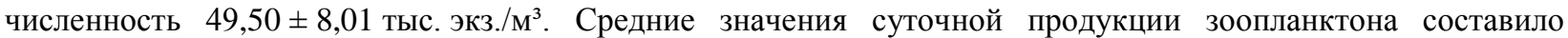
$0,043 \pm 0,020$ г/м³. Проведенный биоценотический анализ позволил выделить в районе исследования пять типов сообществ с доминированием массовых видов коловраток, ветвистоусых и веслоногих рачков. Проведенный двухфакторный анализ показал, что на структуру сообществ сильнее влияют локальные особенности биотопов, чем общие условия на участках исследования. Индекс благополучия указывает, что сообщества зоопланктеров нижнего течения реки Камы находятся в состоянии, близкому к стрессу. По экологической оценке, воды соответствуют умеренно загрязненному классу вод ( $\beta$-мезосапробная зона).

Ключевые слова: экологическое состояние; пространственный анализ; зоопланктон; река Кама; кластерный анализ; оценка уровня самоочищения; Нижнекамское водохранилище; индекс Шеннона; вторичная продукция; биомасса; численность; двухфакторный ANOSIM анализ; индекс сапробности; индекс благополучия.
} 